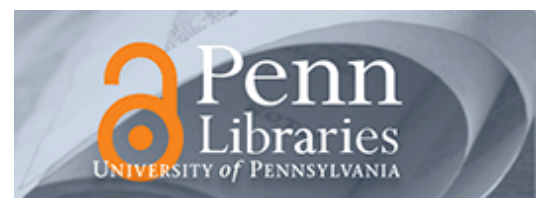

University of Pennsylvania

ScholarlyCommons

$10-2013$

\title{
Legislative Committees as Information Intermediaries: A Unified Theory of Committee Selection and Amendment Rules
}

Attila Ambrus

Eduardo Azevedo

University of Pennsylvania

Yuichiro Kamada

Yuki Takagi

Follow this and additional works at: https://repository.upenn.edu/bepp_papers

Part of the Behavioral Economics Commons

\section{Recommended Citation}

Ambrus, A., Azevedo, E., Kamada, Y., \& Takagi, Y. (2013). Legislative Committees as Information Intermediaries: A Unified Theory of Committee Selection and Amendment Rules. Journal of Economic Behavior \& Organization, 94 (C), 103-115. http://dx.doi.org/10.1016/j.jebo.2013.08.003

This paper is posted at ScholarlyCommons. https://repository.upenn.edu/bepp_papers/125

For more information, please contact repository@pobox.upenn.edu. 


\title{
Legislative Committees as Information Intermediaries: A Unified Theory of Committee Selection and Amendment Rules
}

\author{
Abstract \\ biased against the lobbyist become optimal.

\section{Keywords} \\ informational theories of legislature, committees, lobbying, procedural rules \\ Disciplines \\ Behavioral Economics | Economics
}

This paper considers a model of legislative decision-making, in which information must be collected from a strategic lobbyist. The legislature appoints a committee to communicate with the lobbyist and propose a bill, and determines whether the proposal is processed under open or closed rule. Consistent with empirical evidence, it can be optimal for the legislature to appoint a biased committee and, depending on the lobbyist's bias, both open and closed rule are used in equilibrium. For small lobbyist bias, it is optimal to choose closed rule and a committee whose interests are perfectly aligned with the lobbyist's. For intermediate lobbyist bias, closed rule remains optimal with a committee whose preferences lie between those of the legislature and those of the lobbyist. For large lobbyist bias, open rule and a committee 


\title{
Legislative committees as information intermediaries: a unified theory of committee selection and amendment rules*
}

\author{
Attila Ambrus, Eduardo Azevedo, Yuichiro Kamada and Yuki Takagi ${ }^{\dagger}$ \\ Harvard University
}

16th April 2012

\begin{abstract}
This paper contributes to understanding the role of interest groups in legislative decision-making, and offers an explanation to two widely discussed puzzles concerning the legislative process: why legislative bodies sometimes tie their own hands by delegating power to specialized committees, and why committees consist of preference outliers. In our model, the legislature has to collect information from a strategic lobbyist. Depending on the lobbyist's bias, the legislature either wants to delegate power to a committee aligned with the lobbyist, or retain power but communicate with the lobbyist through an adversely biased committee.
\end{abstract}

${ }^{*}$ We thank Georgy Egorov, Drew Fudenberg, Maxim Ivanov, Navin Kartik, Kenneth Shepsle, and especially Keith Krehbiel for useful suggestions.

${ }^{\dagger}$ Ambrus: Department of Economics, Harvard University, Cambridge, MA 02138, e-mail: ambrus@fas.harvard.edu. Azevedo: Department of Economics, Harvard University, Cambridge, MA 02138, e-mail: azevedo@fas.harvard.edu. Kamada: Department of Economics, Harvard University, Cambridge, MA 02138, e-mail: ykamada@fas.harvard.edu. Takagi: Department of Government, Harvard University, Cambridge, MA 02138, e-mail: takagi@fas.harvard.edu. 


\section{Introduction}

A large body of literature in both political science and economics examines the role of interest groups in the legislative process, and their influence on the legislation. Most scholars of the topic take the position that interest groups can influence legislative decision-making primarily by providing information to legislators that influences their policy preferences. ${ }^{1}$ In line with this, many papers (see for example Rothenberg (1989) and Hansen (1991)) argue that, in a typical situation, it is interest groups that originally possess the relevant information necessary for new legislature, and the first drafts tend to be written by interest groups. Lowi, Ginsberg, Shepsle and Ansolabehere (2010) summarize this point in the following way:

"Interest groups also have substantial influence in setting the legislative agenda and in helping craft specific language in legislation. Today, sophisticated lobbyists win influence by providing information about policies to busy members of Congress. As one lobbyist noted, "You can't get access without knowledge... I can go in to see [former Energy and Commerce Committee chair] John Dingell, but if I have nothing to offer or nothing to say, he's not going to want to see me." (p. 531)

As reflected in the quote above, a large part of the lobbying activity of interest groups involving information provision focuses on influencing the committee that prepares the given bill, before the latter is sent to the legislative body by the committee. Given this, we find two important features of legislative decision-making, discussed in length in the political science literature independently of the topic of lobbying, puzzling. One is why legislative bodies sometimes tie down their own hands and give power to specialized committees, by granting restrictive rules to amending the proposal, thereby giving the committees agenda-setting power. The second puzzle is why many committees consist of preference outliers (members of the legislation whose preferences are biased in some direction, relative to the median member of the legislature). There is an ongoing debate about the extent to which committees are biased. However, most scholars agree that at least some committees consist of preference outliers, and some argue that this is a feature of most committees. ${ }^{2}$ Given that committees are granted some power, why does not the legislature always appoint members to committees whose preferences are close to the median legislator?

In this paper we provide a joint explanation to these two puzzles, utilizing some recent developments in the game theoretic literature of intermediated communication, in a model framework in which committees act

\footnotetext{
${ }^{1}$ An alternative view is that interest groups influence legislation directly by offering monetary contributions in exchange for policy outcomes they favor, reflected for example in Snyder (1991), Diermeier and Myerson (1999), and Grossman and Helpman (1999, 2001). Austen-Smith (1993a) offers a model in which monetary contributions grant interest groups access to politicians with limited time, but they do not directly influence policy decisions. For a survey covering both strands of the literature, see Austen-Smith (1997).

${ }^{2}$ Ray (1980), Weingast and Marshall (1988) and Dion and Huber (1996) present results indicating that many or most committees are outliers, while Krehbiel $(1990,1991)$ and Cox and McCubbins (1993) find that there is no convincing evidence that committees systematically consist of preference outliers. Poole and Rosenthal (1997) find a dramatic shift toward less representative committee contingents among democrative representatives after the 83rd House, concentrated on four committees: Agriculture, Armed Services, Veterans' Affairs, and Education and Labor.
} 
as information intermediators between lobbyists and the legislative body. The model connects two strands of literatures, informational theories of interest groups, and informational theories of legislative committees, started by the seminal paper of Gilligan and Krehbiel (1987; hereafter GK). ${ }^{3}$ The former strand of literature so far abstracted away from the the role of committees in the lobbying process. Informational theories of committees, on the other hand, emphasize the role of committees in gathering specialized information and transmitting it to the legislative body, but they did not model gathering information as interaction with a strategic lobbyist, and focused on the information exchange between a committee and the floor. GK, using the communication model of Crawford and Sobel (1982; hereafter CS), point out that if a committee's preferences differ from the median member of the floor, it does not want to transmit all the information truthfully to the floor. This can provide a rationale for using closed rule, since the latter serves as a commitment by the floor to accept proposals that are biased towards the committee's preferences, inducing the committee to reveal more information truthfully. However, the model of GK does not explain why committees sometimes consist of preference outliers in the first place. If committee members shared the same preferences as the floor's median, strategic information transmission would not be an issue, invalidating the argument for the use of closed rules. ${ }^{4}$

Our model, as opposed to GK, assumes that the information sources of committees are strategic. Those informants (experts, lobbyists) are themselves interested in the policy outcome and might want to withhold valuable information. Formally, we consider a strategic situation with three players: a lobbyist, a committee (a shortcut for the median member of the committee), and the floor (again, a shortcut for the median member of the floor). The game starts with the lobbyist observing the realization of a random variable that influences the preferences of all participants over policy outcomes. The lobbyist then sends a recommendation to the committee. We model communication in this stage of the game as cheap talk. Next, the committee sends a bill to the floor. In case of open rule, this bill is only a recommendation that does not restrict the policy outcomes that the floor can choose among. Hence, with open rule communication is modeled as cheap talk in this stage of the game, too. As opposed to this, in case of closed rule the floor can only choose between the policy outcome corresponding to the committee's bill and an exogenously given status quo. The game

\footnotetext{
${ }^{3}$ Other theories of legislative committees include: (i) the distributive benefits theory, which argues that the power granted to committees is private benefit (pork) to the corresponding members of the legislature; (ii) the majority-party cartel theory, which argues that committees help the ruling party achieve its goals; and (iii) the bicameral rivalry theory, according to which committees serve as hurdles in the legislative procedure that help legislators extract more rents from lobbyists. For a survey paper on the topic, see Groseclose and King (2001).

${ }^{4}$ Gilligan and Krehbiel (1989), Austen-Smith (1993b) and Krishna and Morgan (2001) investigate the possibility of heterogenous committees, whose members can send separate messages to the floor. Krishna and Morgan (2001) show that in case of oppositely biased committee members there exist equilibria in which the committee reveals full information to the floor. The plausability of such equilibria is questioned though in several papers, starting with Krehbiel (2001). Aside from this issue, it is still puzzling why the floor would appoint a heterogenous committee of biased members in the first place, and try to induce a relatively complicated truthtelling equilibrium, instead of appointing a homogenous committee with the same preferences as the floor.
} 
ends with the floor choosing a policy outcome from the set of outcomes allowed by the chosen procedural rule.

Our goal is to examine the above situation from an institutional design viewpoint. In particular, we assume that preceding the game the floor can choose both the preferences of the committee (select the committee) and the procedural rule that would be used to vote on the bill. ${ }^{5}$ We investigate how these choices depend on the bias of the lobbyist, which we assume is commonly known. Note that this framework, among other possibilities, allows for the floor both to appoint a committee with the same preferences as itself (which is essentially equivalent to the floor directly communicating with the lobbyist), and to appoint a committee with the same preferences as the lobbyist (which in case of closed rule is essentially equivalent to delegating proposal power to the lobbyist). ${ }^{6}$

In case of open rule, the (continuation) game we consider is a mediated communication game of the type analyzed in Ivanov (2010) and Ambrus, Azevedo, and Kamada (2009; hereafter AAK). In case of closed rule, the game is equivalent to delegating decision power to the committee subject to a veto power, preceded by a round of cheap talk between the lobbyist and the floor, analyzed in Dessein (2002). Adopting results from the above papers immediately reveals that both in case of choosing closed rule, and in case of choosing open rule, the optimal committee might be biased relative to the floor. ${ }^{7}$

For the case of closed rule, the intuition is that a lobbyist reveals more information to committees whose preferences are more similar to his than the floor's, and who by using the agenda setting power granted by closed rule can effectively represent these preferences. This gives incentives for the floor to appoint a committee that is biased in the same direction as the lobbyist. ${ }^{8}$ For example, if drafting a bill on bank regulation requires inside information from investment banks, the chosen committee under closed rule would be (at least partially) aligned with Wall Street's interests.

In the case of open rule, as Ivanov (2010) shows, there can be mixed equilibria of the cheap talk game

${ }^{5}$ We follow GK in assuming that the floor can ex ante commit to a procedural rule. In practice, the Rules Committee decides what procedural rule to use after the committee submitted the proposal. However, as GK discusses, given that the Rules Committee makes procedural decisions repeatedly with high frequency, reputational concerns are thought to make it possible for the Rules Committee to act according to a precommitted rule of behavior that is ex ante optimal for the floor. GK points out that this is also consistent with empirical evidence on the composition and decisions of the Rules Committee (see also Groseclose and King (2001)).

${ }^{6}$ The tradeoff between delegation and communication is also examined in a technically distinct framework by Aghion and Tirole (1997).

${ }^{7}$ These findings are at odds with those in $\mathrm{Li}$ (2007), which is the first paper we are aware of that introduces a strategic outside expert into the legislative decision-making framework. Li (2007) only analyzes the case of open rule, and only considers pure strategy equilibria. As a consequence, he finds that committees cannot facilitate better information trasmission, and hence the assumption of strategic outside experts does not lead to a theory of committees. As opposed to this, we show that committees can enhance information transmission both in the case of closed and open rules (in the latter case when one allows for mixed strategies).

${ }^{8}$ Kydd (2003) makes the counterpart of this point in the context of mediating conflict resolution: he claims that a party involved in the conflict is more likely to believe a piece of information from a mediator if the latter is "on his side." As opposed to this, in our model, in case of closed rule, what matters is how close the committee's interests to the lobbyist (the original source of information) are, not how close they are to the floor (the ultimate recipient). Clearly, the important difference between our model and Kydd's is that in the latter the information transmission from the original source of information to the mediator is unmodeled. 
with a biased committee serving as an intermediary that are better for the floor than all equilibria of a direct communication game between the lobbyist and the floor. For this to be the case, the committee has to be biased in the opposite direction to the lobbyist. ${ }^{9}$ Such situations are not uncommon in practice. For example, it is a common perception that budget committees consist of members who are fiscally conservative relative to the median legislator, while interest groups are usually positively biased in how much money they want to be allocated to their areas of operation.

The intuition behind the above result is that the noise introduced by the unpredictable behavior of the committee eases the incentive constraints of the lobbyist, inducing him to reveal more information. ${ }^{10}$ For example, a negatively biased budget committee can offset the bias of a positively biased interest group, by sometimes proposing a low budget to the floor even when the original request of the interest group was high. This induces the floor to allocate a relatively high budget even after low proposals from the committee, reducing the gap between how much money the floor allocates when receiving a high versus low proposal from the committee. But this makes a relatively low budget request more attractive for the interest group, in states when their budget need is indeed low, facilitating truthful information transmission.

We find that our theory offers a rich set of predictions regarding the optimal procedure for the floor. When the lobbyist's interests do not differ much from the floor's, the optimal committee has perfectly aligned interests with the lobbyist, and closed rule is used. When the lobbyist's bias becomes larger but not too large, closed rule remains optimal, but the optimal committee has preferences strictly between the lobbyist's and the floor's. Finally, the predictions are reversed when the lobbyist's bias is large enough. In that case, the floor wants to use open rule, and a committee biased against the lobbyist. ${ }^{11}$

Our results might shed some light on the mixed empirical findings on the relationship between committee bias and whether open or closed rule is used. In a series of papers, Dion and Huber $(1996,1997)$ and Krehbiel (1997a,b) offer mixed evidence, with the former papers finding that more biased committees are more likely to be associated with closed rule, and the latter finding the opposite. This is consistent with our finding that there is no simple relationship between absolute value of the committee bias and the rule chosen. The optimality of either closed or open rule is compatible with either small or large committee bias. However,

\footnotetext{
${ }^{9}$ Ivanov (2010) only shows that one of the optimal choices of the principal is appointing an intermediator biased in the opposite direction to the sender. We show that in our model whenever open rule is optimal for the floor, the unique optimal committee is biased in the opposite direction to the sender.

${ }^{10}$ The same outcomes can be obtained in pure strategy equilibrium when there is a small amount of uncertainty regarding the intermediary's (in our case, the committee's) preferences. See the Supplementary Appendix of AAK.

${ }^{11}$ An alternative modeling approach would be assuming that acquiring information requires effort on the part of committee members. Both Gerardi and Yariv (2008) and Che and Kartik (2009) point out that in settings with costly information acquisition, bias can increase incentives to gather information. In our model there are no information acquisition costs, instead we focus on the strategic aspects of acquiring information. Nevertheless, the resulting trade-offs are similar: the committee being better informed but more biased. The above papers do not investigate the interplay between open vs. closed rule (cheap talk vs. delegation) and the bias of the committee (agent). Hence, it is an open question whether a model of costly information acquisition could provide a theory of committee bias and amendment rules that is in line with the empirical observations.
} 
testing the relatively complex predictions that our model provides in this aspect would require more precise data on the preferences of committee members and interest groups than what existing empirical research used.

One simple prediction of our model is that when the procedural rule is endogenously selected, the optimal committee is never more biased in absolute terms than the lobbyist. Moreover, it is strictly less biased unless the lobbyist's bias is small. This is consistent with the finding of Poole and Rosenthal (1997) that lobbyists tend to be more extreme advocates of policy issues than committee members.

\section{Model}

We consider a multi-stage game of legislative decision-making with three players: a lobbyist, a committee and the floor. The outcome of the game is a policy action $x \in \mathbb{R}$. The players' preferences over available policy actions depend on an ex ante unknown state of the world $\theta \in[0,1]$.

The payoffs of the floor, the committee, and the lobbyist are given by $-l(x-\theta),-l\left(x-\theta-b_{C}\right)$, and $-l\left(x-\theta-b_{L}\right)$. We assume that $l$ attains its minimum value of 0 at point 0 . Following standard terminology, we refer to $l$ as the loss function. Note that given $\theta$, the floor's optimal policy is $\theta$, while the optimal policies of the lobbyist and the committee are given by $\theta+b_{L}$ and $\theta+b_{C}$. We refer to $b_{L}$ and $b_{C}$ as the biases of the lobbyist and the committee. Without loss of generality we assume $b_{L} \geq 0$ (the case of a negatively biased lobbyist is perfectly symmetric).

Throughout the main text we restrict attention to the case when $\theta \sim U([0,1])$ and $l(y)=y^{2}$ (this specification is introduced by CS and often referred to as the uniform-quadratic specification). In a Supplementary Appendix we investigate how the qualitative conclusions we derive extend to more general specifications.

We assume that the distribution of the state and the preferences of players are common knowledge.

The game starts with an ex ante stage (stage 0 ), in which the floor selects $b_{C}$ and the procedural rule, which can be either open or closed. ${ }^{12}$

After the ex ante stage, the choices of the floor become commonly known.

In stage 1 , the lobbyist observes the realization of $\theta$, and sends a private message $m \in \mathbb{R}$ to the committee. This message does not directly influence the payoffs and does not change the available actions of players at later stages of the game. Hence, communication between the lobbyist and the committee is assumed to be cheap talk. In real life the message can correspond to a draft proposal written by the lobbyist.

In stage 2 the committee sends a proposal (bill) $p \in \mathbb{R}$ to the floor.

\footnotetext{
12 The specification implies that the floor can appoint an optimal committee, given the exogenously given parameters. For a discussion on exogeneously given committee bias, see Section 4.
} 
Finally, in stage 3 the floor chooses a policy action $x \in \mathbb{R}$. The set of possible choices of the floor in stage 3 depends on the procedural rule chosen in the ex ante stage. In case of open rule, the floor in stage 3 can select any policy action in $\mathbb{R}$. Hence, in this case the communication between the committee and the floor is cheap talk, too. However, in case of closed rule the floor can only choose between $p$, the policy action corresponding to the proposal, and $s \in \mathbb{R}$, an exogenously given status quo policy commonly known from the beginning of the game.

The sequence of moves in the model is depicted on Figure 1.

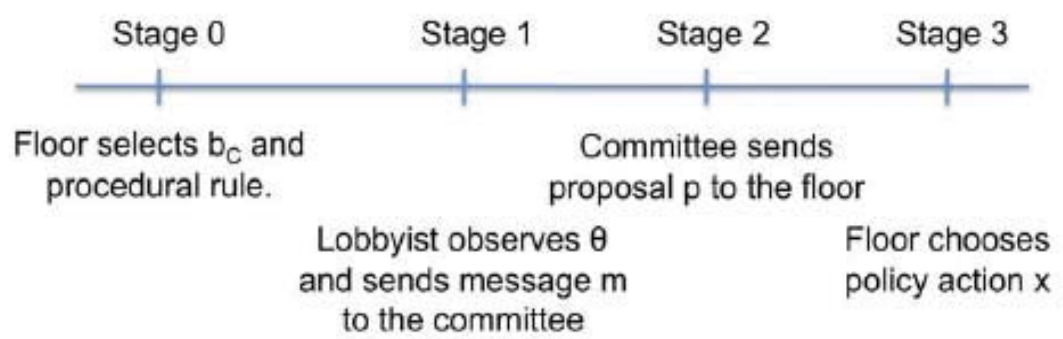

Figure 1: The model's timeline

The solution concept we use throughout the paper is perfect Bayesian Nash equilibrium, as defined in AAK. ${ }^{13}$ From now on we simply refer to it as equilibrium. Moreover, following GK and Krishna and Morgan (2001), we assume that in any subgame following the floor's stage 0 choices, the equilibrium most preferred by the floor prevails.

For analytical convenience, we assume that the status quo policy is so bad that irrespective of the realized state, the floor always accepts the committee's proposal in case of closed rule. A sufficient condition for this is that $l(s-\theta)>l(x-\theta)$, for all $x \in\left[0,1+b_{L}\right]$ and all $\theta \in[0,1]$.

\section{Optimal committee and rule selection}

GK and Dessein (2002) investigate the problem whether an uninformed principal wants to delegate decision power to an informed but biased agent, or just communicate with the agent and retain the decision power. ${ }^{14}$

\footnotetext{
${ }^{13}$ There is no standard definition of perfect Bayesian Nash equilibrium in continuous settings. AAK, besides the usual requirements of sequential rationality and consistency of beliefs, poses an additional weak consistency requirement for beliefs along equilibrium paths that occur with probability 0 .

${ }^{14}$ See also Krishna and Morgan (2001).
} 
They show that delegating decision power can benefit the principal (in our case, the floor), even though it introduces a systematic bias in the policy choice. The intuition is that delegation facilitates more information transmission from the informed party.

Dessein (2002) also extends the above analysis to the case when the principal can delegate decision power to an intermediary, which is exactly the continuation game in our model that results if the floor chose closed rule. The trade-off for the floor in this case is clear: appointing a committee with preferences closer to the lobbyist increases information transmission, at the expense of introducing more bias in the policy choice.

Regarding open rule, as shown in Goltsman et al. (2009), $b_{L} \geq 1 / 2$ implies that there does not exist any mechanism which induces the lobbyist to transmit information. This in particular implies that no strategic committee could induce information transmission, and irrespective of the choice of committee the floor's expected loss is $\frac{1}{12}$, corresponding to a babbling equilibrium (choosing action $x=\frac{1}{2}$ in every state). For biases smaller than this, Ivanov (2010) shows that the loss with an optimal intermediary is the same as when using a nonstrategic mediator as in Goltsman et al. (2009), thereby deriving the maximum ex ante payoff that the floor can achieve when using open rule. In particular, for almost every $b_{L} \in\left(0, \frac{1}{2}\right)$ there exists a value of $b_{C}$ which facilitates an equilibrium that is strictly better for the floor than any equilibrium without appointing a committee (equivalently, when appointing a nonbiased committee). Moreover, the maximum ex ante payoff with open rule can be achieved by appointing a committee with bias between $-2 b_{L}$ and 0 , that is in the opposite direction to the lobbyist (see Figure 2).

The next result combines the above findings. In particular, we show that there is a critical lobbyist bias level $\bar{b}$, below which it is optimal for the floor to use closed rule and above which it is optimal to use open rule. To obtain this critical value, we first conjecture that the optimum closed rule equilibrium near the threshold involves $N=2$ messages (we verify this in the proof). Given this, it can be shown that the loss with closed rule is $\frac{1}{48}+\frac{1}{2} b_{L}^{2}$. Setting this equal to the loss with open rule, shown to be $b_{L}\left(1-b_{L}\right) / 3$ in Ivanov (2010), yields the value of $\bar{b}$ given in the theorem. Although in general it is not known if there is a unique optimal choice of $b_{C}$ in case of open rule, using a result from AAK we show that in the region where open rule is optimal there is indeed a unique optimal choice of $b_{C}$, and it is negative. See the Appendix for the full proof.

Theorem 1. The optimal choices of the floor are given by:

- For $b_{L} \leq \underline{b}=1 / 6$, using closed rule and a committee with interests fully aligned with the lobbyist: $b_{C}^{*}=b_{L}$.

- For $\underline{b}<b_{L}<\bar{b}=\frac{2+\sqrt{3 / 2}}{10}$, using closed rule and a committee with interests strictly between the lobbyist and the floor: $b_{C}^{*} \in\left(0, b_{L}\right)$. 
- For $\bar{b}<b_{L}<1 / 2$, using open rule and a committee with interests opposite to the lobbyist's: $b_{C}^{*}=$ $-\left(1-2 b_{L}\right) / 3<0$.

- For $b_{L} \geq 1 / 2$, either open rule with an arbitrary committee bias, or closed rule with an unbiased committee $b_{C}^{*}=0$ are optimal. In either way, no information is transmitted to the floor.

Figure 2 shows how the optimal committee bias varies with $b_{L}$. The dashed line above the horizontal axis depicts the optimal committee bias under closed rule $\left(b_{C}^{c l}\right)$, and the dashed line below the horizontal axis depicts an optimal committee bias under open rule $\left(b_{C}^{o p}\right)$. As remarked in the previous sections, the relative positions of lobbyist and committee bias are quite distinct under these two possibilities. Under closed rule the floor selects a committee that is biased toward the lobbyist. Furthermore, if $b_{L}$ is small enough, the committee selected has fully aligned interests with the lobbyist. In stark contrast, under open rule the optimal committee is biased in the opposite direction to the lobbyist.

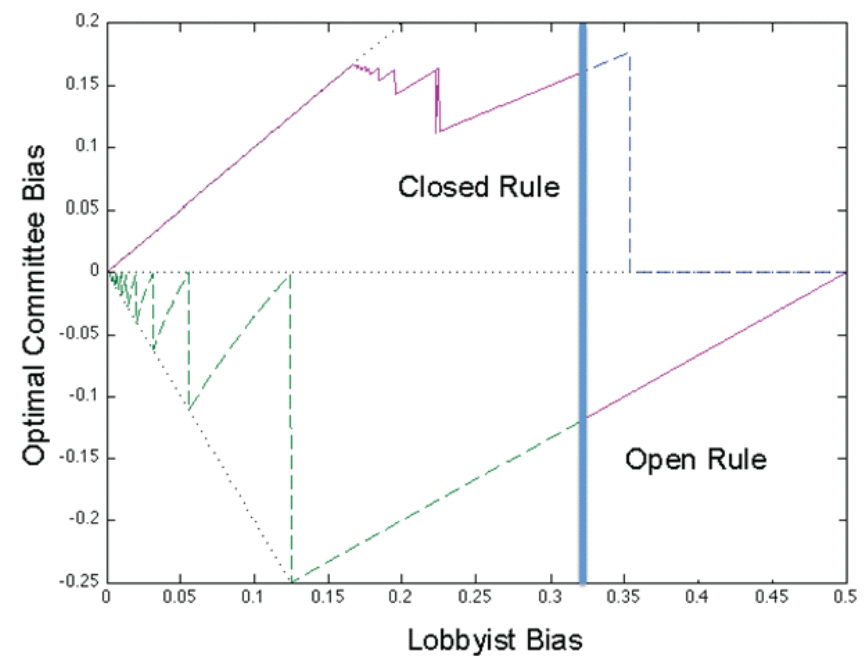

Figure 2: The optimal committee bias, under closed rule (upper half of the picture), open rule (lower half), and endogenously chosen rule (solid line) 


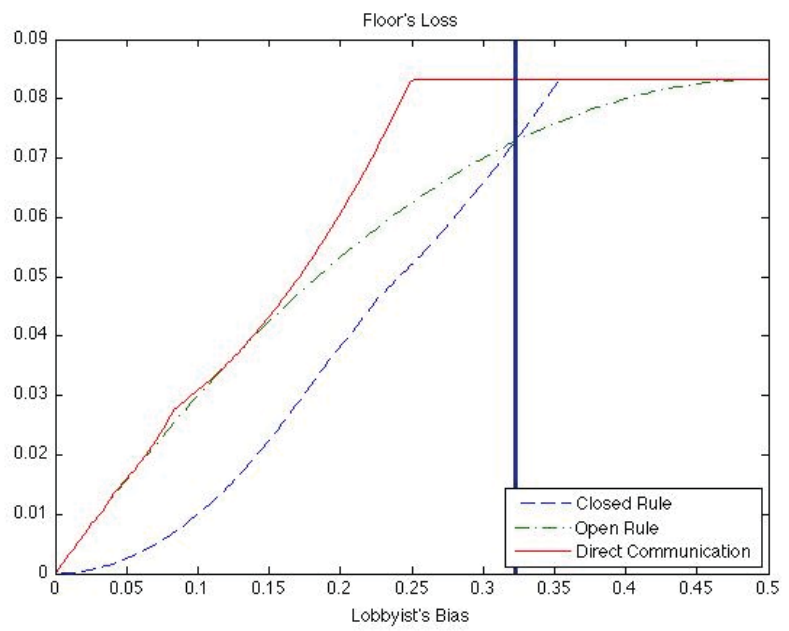

Figure 3: The floor's expected losses with an optimally chosen committee

The solid line in Figure 2 depicts the optimal committee bias taking into account the endogeneity of the rule choice $\left(b_{C}^{*}\right)$. We see that the switching from closed to open rule generates a rich pattern of optimal committee bias. For very low $b_{L}$, closed rule is chosen, and the floor elects a fully captured committee. For biases in an intermediate range, closed rule is chosen, and the floor delegates power to a committee partially aligned with the lobbyist's interests. But, when the divergence between the floor and the lobbyist is large, the floor switches to open rule, and to selecting a committee biased in the opposite direction relative to the lobbyist. For even higher biases the floor induces an uninformed but unbiased choice. ${ }^{15}$

To gain intuition for the above result, first note that the expected payoff of the floor in case of closed rule is equal to the loss resulting from the committee's bias plus the information loss from the communication between the lobbyist and the committee:

$$
U_{F}=-\left[\left(b_{C}^{c l}\right)^{2}+l_{C S}\left(\left|b_{C}^{c l}-b_{L}\right|\right)\right]
$$

where from CS:

$$
l_{C S}(z)=\frac{1}{12 N^{2}}+\frac{z^{2}\left(N^{2}-1\right)}{3} \quad \text { with } \quad N=\left\lceil\frac{\sqrt{1+2 / z}-1}{2}\right\rceil,
$$

where $N$ denotes the size of the partition associated with the most informative equilibrium.

For small $b_{L}$, the loss from biasing the decision by the complete delegation, $b_{L}^{2}$, is second order, but the

\footnotetext{
${ }^{15}$ This can either be achieved through open rule or closed rule, in the latter case requiring an unbiased committee. If there is a small uncertainty regarding the bias of the committee, open rule becomes a strictly better choice for the floor.
} 
loss from imperfect information transmission in the CS model is first order in the bias. ${ }^{16}$ This implies that in case of closed rule, for small $b_{L}$, it is optimal for the floor to appoint a committee which is fully aligned with the lobbyist's interests. Moreover, Ivanov (2010) shows that the floor's loss remains first order in the lobbyist's bias even when an optimally biased intermediator is used. This concludes that for small $b_{L}$, closed rule is a better choice for the floor than open rule.

For intermediate values of $b_{L}$ closed rule remains optimal, but the optimal committee choice trades off making somewhat biased decisions to improve information transmission. The optimal committee bias is highly nonmonotonic in this interval (see Figure 2).

For large values of $b_{L}$ closed rule yields little or no improvement to the floor relative to direct communication, as improving information transmission would require appointing a substantially biased committee. In contrast, the optimal committee under open rule can increase the floor's payoff significantly for such large levels of committee bias. See Figure 3 for the comparison of losses under the two procedural rules and under direct communication between the lobbyist and the floor.

To understand how a biased committee can be beneficial for the floor in case of open rule, first note that committees serve as intermediaries in the communication between the floor and the lobbyist. Such intermediation can improve information transmission between the sender and the receiver of messages, even in a pure cheap talk context. The reason is that for certain types of intermediators there can be mixed equilibria in which the mixing behavior of the intermediary introduces noise into communication in a way that induces the sender to transfer more information.

Figure 4 illustrates such an equilibrium when $b_{L}=\frac{3}{10}$ and the floor selects a committee with $b_{C}=-\frac{2}{15}$. In this case the lobbyist's bias is so large that the only equilibrium in a direct communication game between the lobbyist and the floor would be the noninformative one. In particular, there is no equilibrium with two partition cells, as for any such partition there would be states in the lower cell at which the lobbyist would rather induce the action corresponding to the higher cell than the one corresponding to the lower cell. However, in a game with intermediated communication through a committee with the above bias, there exists a two-cell equilibrium. In this equilibrium the lobbyist partitions the state space into two cells, and sends a message corresponding to the cell that a realized state lies in. The committee sends a "low" proposal after receiving a "low" message from the lobbyist, but mixes between the "low" and "high" proposals after receiving a "high" message from the lobbyist. This behavior raises the action chosen by the floor following a "low" proposal, as with some probability it is sent in high states as well, making the "low" message more

\footnotetext{
${ }^{16}$ From the formula in (1), $1 / N^{2}=2 b+O\left(b^{2}\right)=O(b)$, and $l_{C S}(b)=\frac{1}{12 N^{2}}+\frac{b^{2} N^{2}-b^{2}}{3}=\frac{1}{6} b+\frac{b / 2-b^{2}}{3}+O\left(b^{2}\right)=b / 3+O\left(b^{2}\right)=O(b)$.
} 
attractive for the upward-biased lobbyist. This eases the incentive constraints of the lobbyist in revealing information, and facilitates the informative equilibrium illustrated in the figure. ${ }^{17}$

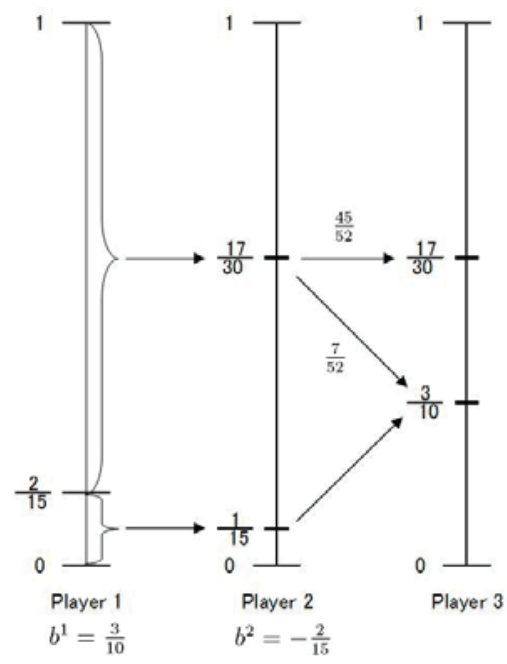

Figure 4: Welfare-improving mixed equilibrium with biased committee

One interpretation of this scenario is that the floor appoints a negatively biased committee because the latter makes it possible that even after high messages from the lobbyist, the implemented action is the lower one, as the negatively biased committee "offsets" the positively biased lobbyist. But exactly because of this, the lower action implemented in this equilibrium is relatively high, which facilitates more information transmission by the lobbyist.

We also note that, as remarked in AAK, in the spirit of Harsányi (1973) the above mixed equilibria can be arbitrarily approximated by pure strategy equilibria of games in which there is a small amount of uncertainty regarding the committee's actual bias. ${ }^{18}$ In these equilibria the committee almost always strictly prefers one equilibrium proposal to any of the other ones, and acts in a deterministic manner. But from the point of view of the floor, the committee's strategy seems to be random. In a similar way, the mixed equilibria we consider can also be approximated by pure strategy equilibria of games in which the committee also receives a (weak) private signal, besides gathering information by talking to the lobbyist. The intuition is the same: the private signal can tilt a committee close to being indifferent between two equilibrium proposals, to either direction.

\footnotetext{
${ }^{17}$ This intuition is similar to why nonstrategic noise can improve information transmission, as in Blume et al. (2007).

${ }^{18}$ See the online supplementary note of AAK. For a cheap talk model in which there can be large uncertainty about a player's preferences, see Li and Madarász (2008).
} 
We conclude this section by noting that Theorem 1 implies that a committee close to the floor's preference is consistent with both closed rule (when the lobbyist's bias is very small) and open rule (when the lobbyist's bias is very large). Similarly, a substantially biased committee is also consistent with both open and closed rule (when the lobbyist's bias is in an intermediate range). These observations apply, despite the fact that the optimal rule is monotonic in the magnitude of the lobbyist's bias (but the relationship between the optimal rule and the committee bias is nonmonotonic).

\section{Discussion}

Here we discuss two modifications of the model presented above.

\subsection{Exogenous committee bias}

So far the analysis assumed that the floor can select the optimal committee, given the bias of the relevant lobbyist. This essentially assumes that a separate ad-hoc committee is created to process each bill. While this is a good approximation of how the legislative process worked in the early years of the Congress and the Senate in the United States (see Canon and Stewart (2001)), efficiency considerations led to a system where standing committees consisting of infrequently changing membership are responsible for proposing most amendments to the floor.

Our model is still a good approximation of the process if the jurisdiction of standing committees is specified in a way that all the relevant interest groups that a given committee consults have roughly the same bias. Nevertheless, the prevalence of standing committees in the legislative process makes it important to analyze the case when the committee bias is exogenously given, and ex ante the floor can only choose the procedural rule.

The first observation we make is that Theorem 1 implies that if $b_{L}>\overline{\bar{b}}=1 / \sqrt{8}$ then open rule is better than closed rule. This is because in this region choosing closed rule yields a payoff to the floor that is strictly worse than its payoff in babbling equilibrium, for any $b_{C} \neq 0$. Hence, closed rule cannot be optimal if the lobby's bias is too large.

The second straightforward observation to make is that $b_{C}>\left(\frac{1}{12}\right)^{\frac{1}{2}}$ implies that the loss of the floor from the biasedness of the committee's decision in case of closed rule exceeds the informational loss in the babbling equilibrium. ${ }^{19}$ Hence, closed rule cannot be optimal if the committee's bias is too large.

\footnotetext{
$19 \frac{1}{12}$ is the variance of $\theta$ uniformly distributed over $[0,1]$.
} 
Third, the next result states that closed rule cannot be optimal if the committee is biased in the opposite direction to the lobbyist.

Theorem 2. If $b_{C}<0$ then open rule is strictly better for the floor than closed rule.

The intuition behind this result is easy to see: The floor's payoff under open rule is the same as that under direct communication between the lobbyist and the floor, as shown in AAK. Since the committee's interests are further away from the lobbyist than the floor's, the committee's payoff under closed rule is no more than this direct communication payoff of the floor. But the committee's payoff is strictly greater than the floor's payoff under closed rule, as the committee's decision is biased.

The above result, together with the preceding two observations imply that the region in the $b_{L} \times b_{C}$ space where closed rule is better than open rule is contained in the box defined by the two axis and the lines $b_{L}=1 / \sqrt{8}$ and $b_{C}=\frac{1}{6} \sqrt{3} \cdot{ }^{20}$

Within this region we use numerical analysis to compare the floor's payoff between using open and closed rule. For any $\left(b_{L}, b_{C}\right)$ pair, the floor's ex ante payoff in case of using closed rule is easily computable, as the sum of $-b_{C}^{2}$ and the informational loss in the maximum partition direct communication equilibrium between the lobbyist and the committee. On the other hand, in general we cannot compute the floor's ex ante payoff when using open rule, as there is no known characterization of the best equilibrium for intermediated communication for general $\left(b_{L}, b_{C}\right)$ pairs. However, it is possible to obtain bounds on the latter payoffs, leading to an incomplete characterization of the region where closed rule is better than open rule.

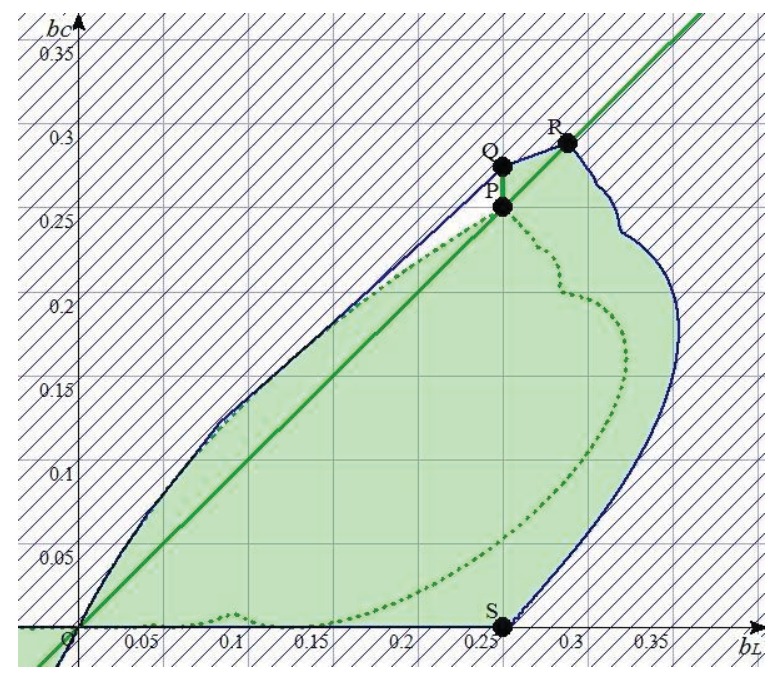

Figure 5: Optimality of closed vs. open rule for different biases of the lobbyist and the committee

\footnotetext{
${ }^{20}$ This is under the assumption that $b_{L}>0$. There is a corresponding region in the half space defined by $b_{L}<0$.
} 
First, we observe that whenever the best pure strategy equilibrium under open rule - which is fully characterized in AAK - yields a higher payoff for the floor than its payoff under closed rule, the latter is clearly suboptimal. The set of $\left(b_{L}, b_{C}\right)$ pairs where this is the case is depicted on Figure 5 as the area marked with diagonal lines texture, outside the bounded region surrounded by curves OQ, QR, RS, and SO. We will refer to the remaining set of bias pairs (where the closed rule can be better than the open rule) as the OQRS region.

Second, both Proposition 5 of AAK and Lemma 4 of Ivanov (2010) imply that below the 45-degree line the best equilibrium under open rule is a pure strategy one. This implies that in the OQRS region closed rule is indeed better than open rule for all the points below the 45-degree line.

Third, the payoff of the floor when using open rule with a given committee bias is bounded from above by $-b_{L}\left(1-b_{L}\right) / 3$, which is shown in Goltsman et al. (2009) to be the maximum payoff of the floor when using a nonstrategic intermediator to communicate with the lobbyist. Hence, when the latter is smaller than the payoff that can be attained by closed rule, it is surely suboptimal. This consideration establishes that in points enclosed by the dotted curve, closed rule is better than open rule.

Finally, AAK show that there is no mixed equilibrium with two possible actions induced in equilibrium if $b_{C}>b_{L}>0.25$. The arguments can be extended to show that there is no nontrivial mixed equilibrium whatsoever in this region. As this extension is straightforward, we omit it from the current paper. This reasoning implies that at points in the OQRS region that are above the 45-degree line and to the right of the $b_{L}=0.25$ line, closed rule is optimal.

The $\left(b_{L}, b_{C}\right)$ pairs for which the above arguments establish the optimality of closed rule are depicted as the shaded region. The small white region surrounded by curves OQ, QP, and PO represents the remaining set of $\left(b_{L}, b_{C}\right)$ pairs, at which the above arguments do not determine whether open or closed rule is better.

Summarizing the findings, the analysis reveals similar qualitative findings regarding optimal procedural rules as in the endogenous committee bias case: closed rule is optimal if the bias of the lobbyist is not too large, and the committee's bias is in the same direction as the lobbyist's bias but not too biased relative to the latter.

\subsection{Endogenously chosen status quo}

Mylovanov (2008) shows that in a setting analogous to ours, delegating decision power to the informed player, subject to veto power by the principle, can achieve the same ex ante payoff for the principal as the optimal arbitration rule, provided that the status quo outcome can be freely selected by the floor ex ante. ${ }^{21}$

\footnotetext{
${ }^{21}$ The terminology arbitration rule is introduced in Goltsman et al. (2008). Other papers in the economics literature refer to it as a constrained delegation schedule without monetary transfers (see for example Holmstrom (1977), Melumad and Shibano
} 
Arbitration implies that the principal can ex ante commit to a possibly stochastic policy choice after any possible message from the informed agent. If such commitment is possible, the principal can achieve an at least weakly higher payoff than its optimal payoff in the game we analyzed in Section $3 .^{22}$

An important implication of the above result is that with endogenously selected status quo, closed rule is always (at least weakly) better for the floor than open rule. This is a stark result, and it does not conform with the empirical observations on legislative decision-making. However, in most cases the assumption that the status quo outcome can be endogenously selected is unrealistic. A procedure like that would involve first working out a proposal that changes the current status quo to the one that the floor finds it optimal to select ex ante. This would require creating a different (unbiased) committee than the one working out the final proposal, doubling the workload of the legislature, and lengthening the legislative procedure. Nevertheless, we regard the optimality of closed rule under endogenously selected status quo as an intriguing theoretical result, with possible implications to future institutional design in legislatures. ${ }^{23}$

\section{Conclusion}

The findings of this paper show that the relatively complicated patterns of committee biases and procedural rules observed in legislative decision-making can be explained by a model in the tradition of the informational theories of committees. Namely, if the legislative process requires informational input from outside interest groups, it can be in the legislature's interest to appoint a biased committee to communicate with the expert. The use of both open and closed rule can be optimal, depending on the interest group's bias, and there is no monotonic relationship between the absolute bias of the committee and the procedural rule implemented. A testable new prediction of our model is that closed rule tends to be associated with committees biased in the same direction as the relevant interest groups the committee gathers information from, while open rule tends to be associated with committees that are either representative of the floor median, or biased in the opposite direction to the relevant interest groups.

(1991), Alonso and Matouschek (2008) and Kováč and Mylovanov (2009)).

${ }^{22}$ The floor can potentially achieve an even higher payoff if it makes different proposals differentially costly for the committee, through bureaucratic procedural rules, as in Ambrus and Egorov (2009). We do not pursue this direction here.

${ }^{23}$ An existing institutional channel that can potentially be used in implementing the above optimal arbitration outcome is discharge petitions. Any member of legislature may file such a petition calling for a measure to be brought out of a committee. When half of the House members (218) have signed the petition, the measure is taken away from the committee and considered on the floor. If the floor can commit to carry out such an action only if the committee proposal is above a cap corresponding to the ex ante optimal status quo outcome, the threat of discharge petition implements the optimal arbitration scheme. This possibility is consistent with the fact that discharge petition is often used as a threat, and that in the past three decades there have been an increase in both the use of closed rule and in the number of discharge petitions (see Burden (2005) and Theriault $(2009))$. 


\section{Appendix}

\subsection{Proof of Theorem 1}

To prove Theorem 1, we begin by collecting some results from the existing literature.

Conditional on selecting closed rule, the optimal committee choice of the floor is characterized in Dessein (2002).

Proposition A1 (Proposition 5 Dessein (2002)) Under closed rule, the floor always elects a committee with bias $b_{C}^{c l} \in\left[0, b_{L}\right]$. Furthermore,

- If $0 \leq b_{L} \leq \underline{b}=1 / 6$, the optimal committee is fully aligned with the lobbyist's interests: $b_{C}^{c l}=b_{L}$.

- If $\underline{b}<b_{L}<\overline{\bar{b}}=1 / \sqrt{8}$, the optimal committee has a bias strictly between the floor's and the lobbyist's: $b_{C}^{c l} \in\left(0, b_{L}\right)$.

- If $b_{L}>\overline{\bar{b}}$, the optimal committee is fully aligned with the floor's interests: $b_{C}^{c l}=0$.

In the case of open rule, Ivanov (2010) shows the following result.

Proposition A2 (Ivanov 2010) Under open rule, and $b_{L} \leq 1 / 2$, the floor's minimum loss with an endogenously selected committee is

$$
l_{O R}^{*}=b_{L}\left(1-b_{L}\right) / 3,
$$

and it can be attained with a committee with bias $b_{C}^{o p} \in\left(-2 b_{L}, 0\right]$.

In addition to these two results, we will need an auxiliary result, Lemma 1 , before proving Theorem 1. Although Proposition A2 characterizes the payoffs attainable under the open rule, the results in Ivanov do not fully characterize the optimal committee bias. Therefore we use Lemma 1 in the proof of Theorem 1 to characterize the optimal committee bias, in the case where the open rule is optimal. For Lemma 1, we will use some terminology from AAK. In Proposition 4 (and in greater detail in Section 3 of the online supplementary note) of AAK it is shown that any equilibrium can be partitioned in a finite number of components, such that whenever the lobbyist announces a state in a component, the committee mixes only between adjacent actions in that component. We will denote a component with $K$ actions as a $K$-component.

Lemma 1. If $b_{L}>\bar{b}$ and $K \geq 4$, then there is no equilibrium with a $K$-component. 
Proof of Lemma 1. Suppose in the contrary.

Let the boundaries of the interval partition of a component be $t_{0}, \ldots, t_{K}$, with $t_{k-1}<t_{k}$ for all $k=$ $1, \ldots, K$, where $t_{0}$ and $t_{K}$ are the endpoints of the component itself. Let the equilibrium actions be $x_{1}, \ldots, x_{K}$ with $x_{k-1}<x_{k}$ for all $k=2, \ldots, K$.

First suppose $b_{C}>0$. Then we know that $b_{C}>b_{L}$ from Proposition 5 of AAK. After messages $k=1, \ldots, 3$, the committee is indifferent between $x_{k} \leq \frac{t_{k}+t_{k-1}}{2}$ and $x_{k+1}$. This implies that $x_{k+1}-x_{k} \geq 2 b_{C}$ for every $k=1, \ldots, 3$ (otherwise the committee would prefer the higher message of the two). Hence, $t_{K}-t_{0} \geq 6 b_{C}>1$, a contradiction.

Next, suppose $b_{C}<0$.

First, note that $x_{2}-t_{1}>b_{L}$. This is because at $t_{1}$ the lobbyist is indifferent between inducing $x_{1}$ and $x_{2}>t_{1}$, which is inconsistent with $x_{2}-t_{1} \leq b_{L}$ (in this case he should strictly prefer $x_{2}$ to $x_{1}$ ). Second, note that $x_{K}-t_{K-1}>b_{L}$, otherwise at $t_{K-1}$ the committee would strictly prefer sending the highest message in the component). Third, note that $t_{K}-x_{K}>b_{L}$, since $x_{K}-t_{K-1}>b_{L}$ (as shown in the previous step) and because $x_{K}$ is the midpoint of $t_{K-1}$ and $t_{K}$. Fourth, note that $\frac{t_{K-1}+t_{K-2}}{2}-x_{K-2}>\left|b_{C}\right|$, otherwise when receiving the second highest message, the committee would strictly prefer $x_{K-2}$ to $x_{K-1}$, contrary to the assumed equilibrium.

The above arguments establish that

$$
t_{K}-t_{0}>3 b_{L}+t_{K-1}-x_{K-2}>3 b_{L}+\frac{t_{K-1}+t_{K-2}}{2}-x_{K-2}>3 b_{L}+\left|b_{C}\right|
$$

Consider first $\left|b_{C}\right| \geq 0.04$. Then $b_{L}>0.32$ and inequality (3) imply $t_{K}-t_{0}>1$, a contradiction.

Consider next $\left|b_{C}\right|<0.04$. This implies $x_{K}-x_{K-1}=2\left|b_{C}\right|<0.08$. Then $x_{K}-t_{K-1}>b_{L}$ implies that $x_{K-1}-t_{K-1}>0.24$, which implies $x_{K-1}-\frac{t_{K-1}+t_{K-2}}{2}>0.24$. Then $\frac{t_{K-1}+t_{K-2}}{2}-x_{K-2}>0.24+2\left|b_{C}\right|$, otherwise when receiving the second highest message, the committee would strictly prefer $x_{K-2}$ to $x_{K-1}$, contrary to the assumed equilibrium. Then inequality (3) leads to a contradiction.

Having collected these results, we can proceed to the proof of Theorem 1. Propositions A1 and A2 are used to derive the boundary between the regions where the open or closed rule is optimal. Proposition A1 then characterizes the optimal committee bias in the closed rule region. In the open rule region, the characterization of the optimal committee bias depends on a more detailed argument based on Lemma 1.

Proof of Theorem 1. The argument builds on Propositions A1 and A2. Since $\bar{b}=\frac{2+\sqrt{3 / 2}}{10}<1 / \sqrt{8}=\overline{\bar{b}}$, it only remains to be shown that (i) closed rule is optimal for $b_{L}<\bar{b}$ and open rule for $b_{L}>\bar{b}$; and (ii) for $b_{L}>\bar{b}$ the optimal committee bias given open rule is as stated in Theorem 1. 
First, we prove (i).

In the range $b_{L} \in(0,1 / 4)$, using closed rule with $b_{C}=b_{L}$ gives a loss of $b_{L}^{2}$, which is strictly less than the loss with open rule given by equation (2), which is $b_{L}\left(1-b_{L}\right) / 3$.

In the range $b_{L} \in[1 / 4, \bar{b})$, using closed rule with $b_{C}=b_{L} / 2$ results in a partition of size $N=2$ and a loss of

$$
b_{C}^{2}+l_{C S}\left(b_{L}-b_{C}\right)=b_{C}^{2}+\frac{1}{48}+\left(b_{L}-b_{C}\right)^{2}=\frac{b_{L}^{2}}{2}+\frac{1}{48},
$$

which is also strictly less than $b_{L}\left(1-b_{L}\right) / 3$.

Now we have to show that, in the range $b_{L} \in(\bar{b}, 1 / 2)$, open rule is strictly better. Take $b_{L}$ in this range, and assume by contradiction that there exists $b_{C}$ in $\left[0, b_{L}\right]$ such that closed rule with a committee with bias $b_{C}$ has a loss no more than $b_{L}\left(1-b_{L}\right) / 3$. This in particular implies that $b_{C}^{2} \leq b_{L}\left(1-b_{L}\right) / 3$. Rearranging, this implies

$$
b_{L}-b_{C} \geq \frac{4 b_{L}^{2}-b_{L}}{3\left(b_{L}+b_{C}\right)} \geq \frac{4 b_{L}^{2}-b_{L}}{6 b_{L}}=\frac{2}{3} b_{L}-\frac{1}{6}>\frac{2}{3} \bar{b}-\frac{1}{6}>0.048
$$

This and the formula for the size of partitions in the CS equilibria given in the text imply that the number of partitions under closed rule equilibrium is $N \leq 3$. So we only have to check that, for the three cases $N=1,2$, and 3 , there is no $b_{C}$ such that closed rule is weakly better. We omit this straightforward verification.

What remains to show is (ii), i.e. that for $b_{L} \in\left(\bar{b}, \frac{1}{2}\right)$ the optimal committee bias is as stated. It is straightforward to check that the committee bias in the proposition yields the minimum loss to the floor. Indeed, Ivanov (2010) uses a committee with this bias in the proof of Proposition A2. Therefore, we only have to prove that this optimal committee bias is unique, in the region where the open rule is optimal. The idea of the proof is to show that the optimal equilibrium must have a very specific structure: the lobbyist's partition has two possible messages, and a negatively biased committee only mixes when receiving the higher message. That is, the equilibrium partition is composed of a single 2-component. Then it is easy to explicitly describe equilibrium and calculate the unique optimal bias.

The first step in the proof is proving that in the given range, equilibria with any committee cannot have components with four or more actions. This is shown in Lemma 1 above.

Furthermore, in AAK Section 4.2 and online supplementary note Section 2.2 the authors completely characterize equilibria with a single 3 -component, and in particular show that if $\left|b_{L}\right|>1 / 10$ then there cannot be such equilibria. This result also implies that there cannot be any equilibrium with a 3-component, since the equilibrium play within such a component would correspond to a single 3-component equilibrium with a restricted state space corresponding to the component. Given such a state space, the AAK characterization implies that there cannot be an equilibrium consisting of a single 3-component. This concludes that for any committee, equilibria can at most have 2-components. 
Equilibria with 2-components are easy to characterize. Consider a 2-component with endpoints $t_{0}, t_{1}, t_{2}$. By the characterization in Section 2.1 of the online supplementary note to AAK, we have that

$$
t_{2}-t_{1}=2\left(b_{L}-b_{C}\right)
$$

Also, for $b_{L}>\bar{b}$, we have $b_{C} \leq 0$. So $t_{2}-t_{1} \geq 2 \bar{b}>0.64$. In particular, there can be no equilibria with two or more 2-components. Also, if an equilibrium has a 2-component with a 1-component on either the right or the left, the indifference condition of the lobbyist gives that one of these components has to have size at least $4 b_{L}>1$. So no equilibria with both 1-components and 2-components exist.

Because CS show that no informative equilibria composed exclusively of 1-components exist, we have that the only possibility for a non-babbling equilibrium consists of a single 2-component. This case is fully characterized in Section 2.1 of the online supplementary note to AAK. In the case $b_{C} \geq 0$, a straightforward calculation shows that it is not possible to improve on direct communication. In the case $b_{C}<0$, the component is partitioned by the point $t_{1}=1-2\left(b_{L}-b_{C}\right)$. Having this characterization of the equilibrium partition, one can simply calculate the loss of using a given committee bias $b_{C}$. It is given by

$$
\frac{1}{3}+\Delta(1+\Delta)+b_{C}(1+2 \Delta)
$$

where $\Delta=b_{C}-b_{L}$. This gives the unique value of the optimal bias $b_{C}=-\left(1-2 b_{L}\right) / 3$.

\subsection{Proof of Theorem 2}

Proof of Proposition 2. First, notice that the floor's payoff under closed rule is worse than the committee's payoff by $b_{C}^{2}>0$. Hence, it suffices to show that the floor's payoff under open rule is weakly greater than the committee's payoff under closed rule. To see this, we show that the floor's payoff in a pure strategy equilibrium under open rule is weakly greater than the committee's payoff under closed rule.

Proposition 2 in AAK implies that a necessary and sufficient condition for a strategy profile to constitute a pure strategy equilibrium under open rule is that the lobbyist's and the floor's strategies correspond to an equilibrium in direct communication between them, and that two adjacent actions that are put positive probabilities have distance at least $2\left|b_{C}\right|$ between them. On the other hand, by the same proposition, a necessary and sufficient condition for a strategy profile to constitute an equilibrium under closed rule is that the lobbyist's and the committee's strategies correspond to an equilibrium in direct communication between them, and that two adjacent actions that are put positive probabilities have distance at least $2\left(b_{L}-b_{C}\right)$ between them. Since $2\left(b_{L}-b_{C}\right)>2\left|b_{C}\right|$, the payoff that the committee achieves under closed rule can always 
be attained by the floor under open rule. Thus the proof is complete.

\section{References}

Aghion, P. and J. Tirole (1997): "Formal and Real Authority in Organizations," Journal of Political Economy, 105, 1-29.

Alonso, R. and N. Matouschek (2008): "Optimal delegation," Review of Economic Studies, 75, 259-293.

Ambrus, A., E. Azevedo and Y. Kamada (2009): "Hierarchical cheap talk," mimeo, Harvard University.

Ambrus, A. and G. Egorov (2009): "Delegation and nonmonetary incentives," mimeo, Harvard University.

Austen-Smith, D. (1993a): "Information and influence: Lobbying for agendas and votes," American Journal of Political Science, 37, 799-833.

Austen-Smith, D. (1993b): "Interested experts and policy advice: Referrals under open rule," Games and Economic Behavior, 5, 3-43.

Austen-Smith, D. (1997) "Interest Groups: Money, Information and Influence," in Dennis Mueller (ed.) Perspectives on Public Choice. London: Cambridge University Press.

Blume, A., O. Board, and K. Kawamura (2007): "Noisy Talk", Theoretical Economics, 2, 395-440.

Burden, B. (2005): "The Discharge Petition as Minority Party Strategy," mimeo, Harvard University.

Canon, D. T. and C. Stewart III (2001): "The evolution of the committee system in congress," IN L. C. Dodd and B. I. Oppenheimer (ed.s): Congress reconsidered, Washington DC: CQ Press, 163-190.

Che, Y. and N. Kartik (2009): "Opinions as incentives," Journal of Political Economy, 117, 815-860.

Cox, G. W. and M. D. McCubbins (1993): Legislative Leviathan: Party government in the house, Berkeley: University of California Press.

Crawford, V. and J. Sobel (1982): "Strategic information transmission," Econometrica, 50, 1431-1452.

Dessein, W. (2002): "Authority and communication in organizations," Review of Economic Studies, 69, 811-838.

Diermeier, D. and R. Myerson (1999): "Bicameralism and its consequences for the internal consequences of legislatures," American Economic Review, 89, 1182-1196.

Dion, D. and J. Huber (1996): "Procedural choice and the house committee on rules," Journal of Politics, $58,25-53$.

Dion, D. and J. Huber (1997): "Sense and sensibility: The role of rules," American Journal of Political Science, 41, 945-958.

Gerardi, D. and L. Yariv (2008): "Costly expertise," American Economic Review (Papers 83 Proceedings), 98, 187-193. 
Gilligan, T. W. and K. Krehbiel (1987): "Collective decision-making and standing committees: An informational rationale for restrictive amendment procedures," Journal of Law, Economics and Organization, $3,287-335$.

Gilligan, T. W. and K. Krehbiel (1989): "Asymmetric information and legislative rules with a heterogeneous committee," American Journal of Political Science, 33, 459-490.

Goltsman, M., J. Hörner, G. Pavlov and F. Squintani (2009): "Mediation, arbitration and negotiation," Journal of Economic Theory, 144, 1397-1420.

Groseclose, T. and D. C. King (2001): "Committee theories reconsidered," IN L. C. Dodd and B. I. Oppenheimer (ed.s): Congress reconsidered, Washington DC: CQ Press, 191-216.

Grossman, G. and E. Helpman (1999): "Competing for endorsements," American Economic Review, 89, $501-524$.

Grossman, G. and E. Helpman (2001): Special interest politics, Cambridge and London, MIT Press.

Hansen, J. M. (1991): Gaining access: Congress and the farm lobby, 1919-1981, Chicago: Chicago University Press.

Harsányi, J.C. (1973): "Games with randomly disturbed payoffs: a new rationale for mixed-strategy equilibrium points," International Journal of Game Theory, 2, 1-23.

Holmstrom, B. (1977): "On incentives and control in organizations" (PhD dissertation, Stanford University).

Ivanov, M. (2010): "Communication via a strategic mediator," Journal of Economic Theory,, 145, 869884 .

Kováč, E. and T. Mylovanov (2009): "Stochastic mechanisms in settings without monetary transfers," Journal of Economic Theory, 144, 1373-1395.

Krehbiel, K. (1990): "Are congressional committees composed of preference outliers?, American Political Science Review, 84, 149-163.

Krehbiel, K. (1991): Information and legislative organization, Ann Arbor: University of Michigan Press.

Krehbiel, K. (1997a): "Restrictive rules reconsidered," American Journal of Political Science, 41, 929-944.

Krehbiel, K. (1997b): "Rejoinder to sense and sensibility," American Journal of Political Science, 41, 958-964.

Krehbiel, K. (2001): "Plausability of signals by a heterogeneous committee," American Political Science Review, 95, 453-456.

Krishna, V. and J. Morgan (2001): "Asymmetric information and legislative rules," American Political Science Review, 95, 435-452. 
Kydd, A. (2003): "Which side are you on? Bias, credibility, and mediation," American Journal of Political Science, 47, 597-611.

Li, M. and K. Madarász (2008): "When mandatory disclosure hurts: Expert advice and conflicting interests," Journal of Economic Theory, 139, 47-74.

Li, T. (2007): "The messenger game: Strategic information transmission through legislative committees," Journal of Theoretical Politics, 19, 489-501.

Lowi, T. J., B. Ginsburg, K. A. Shepsle and Stephen Ansolabehere (2010): American Government: Power and Purpose, 11th Edition, New York: Norton.

Melumad, N. and T. Shibano (1991): "Communication in settings with no transfers," Rand Journal of Economics 22, 173-198.

Mylovanov, T. (2008): "Veto-based delegation," Journal of Economic Theory, 138, 297-307.

Poole, K. and H. Rosenthal (1997): Congress: A politicaleconomic history of roll call voting, Oxford: Oxford University Press.

Ray, B. A. (1980): "The responsiveness of the U.S. congressional armed services committees to their parent bodies," Legislative Studies Quarterly, 5, 501-515.

Rothenberg, L. S. (1989): "Putting the puzzle together: Why people join public interest groups," Public Choice, 60, 241-257.

Snyder, J. (1991): "On buying legislatures," Economics and Politics, 3, 93-109.

Theriault, S. (2009): "The procedurally polarized congress," mimeo, University of Texas at Austin.

Weingast, B. R. and W. J. Marshall (1988): "The industrial organization of congress; or Why legislatures, like firms, are not organized as market," Journal of Political Economy, 96, 132-63. 